\title{
A FOTOGRAFIA INSTITUCIONAL NA ORGANIZAÇÃO DO CONHECIMENTO ARQUIVÍSTICO: COMPREENDENDO O PROCESSO DE EVIDENCIAÇÃO DOCUMENTAL COMO PARÂMETRO DE ORGANIZAÇÃO
}

\author{
INSTITUTIONAL PHOTOGRAPHY IN ARCHIVAL \\ KNOWLEDGE ORGANIZATION: UNDERSTANDING THE \\ PROCESS OF DOCUMENT EVIDENCE AS AN \\ ORGANIZATIONAL PARAMETER
}

Bruno Henrique Machado a

Rafael Semidão ${ }^{b}$

Telma Campanha de Carvalho Madio ${ }^{c}$

Daniel Martínez-Ávila d

\begin{abstract}
RESUMO
Introdução: A inserção da fotografia no quadro dos documentos arquivísticos é relativamente recente, nesse sentido, a fotografia ainda encontra dificuldades teóricas metodológicas a respeito das aplicações das funções arquivísticas basilares da Arquivologia. Nesse sentido, é preciso refletir a respeito desse documento na organização do conhecimento arquivístico. Objetivo: Propõe-se apresentar reflexões sobre a fotografia na organização do conhecimento arquivístico, apresentando as peculiaridades de tratamento que envolvem este tipo de documento em suporte convencional e digital e uma reflexão sobre sua organização a partir de seu processo de evidenciação na produção institucional. Metodologia: Pesquisa de abordagem metodológica qualitativa de cunho teórico e reflexivo. Resultados: Como principal proposição é apresentada uma abordagem que toma o princípio da proveniência como elemento de análise para se identificar o processo de trabalho que é evidenciado no
\end{abstract}

a Mestre em Ciência da Informação pela Universidade Estadual Paulista (UNESP). Doutorando do Programa de Pós-Graduação em Ciência da Informação. E-mail: machadobrunohenrique@gmail.com

b Doutor em Ciência da Informação Universidade Estadual Paulista (UNESP). Professor da Universidade Federal do Rio Grande. E-mail: rafaelsemidao@gmail.com

c Doutora em Comunicação Social pela Universidade de São Paulo (USP). Professora do Departamento de Ciência da Informação da Universidade Estadual Paulista (UNESP). E-mail: telma.madio@unesp.br

d Doutorado internacional pelo Programa Oficial de Doctorado en Documentación pela Universidad Carlos III de Madrid. E-mail: dmartinezavila@gmail.com 
documento arquivístico fotográfico como aspecto comunicativo e, sobretudo, como aspecto de práxis. Conclusões: Com base na identificação desse processo é sugerido uma concepção de organização do conhecimento registrado na fotografia que favoreça o diálogo entre o contexto de produção e o contexto de uso desse documento.

Descritores: Arquivologia. Organização do conhecimento. Fotografia. Documento arquivístico.

\section{INTRODUÇÃO}

Após a invenção da técnica fotográfica no século XIX, foi-se concedendo à fotografia um grande poder de documentar e representar descobertas científicas, realizar registros do desenvolvimento da arquitetura das cidades e indústrias, e demais formas de uso que têm marcado a história da fotografia como meio de registro documental de feitos sociais em geral.

Dentre esses feitos sociais, Charles Baudelaire já reivindicava no "Salão de 1859" o "verdadeiro dever" da fotografia como serva das artes e das ciências (BAUDELAIRE, 1972). Nesse sentido, além da arte, a fotografia tem possibilitado a manutenção da presença do passado captado pela imagem fixa, que se presta a preencher as lacunas da memória humana, pois, inexoravelmente, tal memória biológica é incapaz de "gravar" todos os acontecimentos da vida, sendo preciso, por isso, esquecer para lembrar; e a fotografia, dessa maneira, auxilia na "colagem" dos fragmentos da história humana (SONTAG, 2004).

Ampliando o espectro daquilo que se entende por memória, Tagg (2007) apresenta as configurações que a fotografia adquire para além da função de registro da memória individual/coletiva, destacando seu caráter de documentação socio-institucional. Segundo o autor, a fotografia foi inserida em instituições emergentes de tipo médico, legal e governamental, que atribuíram às fotografias o valor de evidência, com decorrente valor de fonte de prova. Precisamente por isso, Tagg (2007) é taxativo ao afirmar que as fotografias são produzidas sob a perspectiva de um discurso institucional.

Esse discurso seria engendrado como a materialização de uma ação, integrante do quadro de funções que constitui a atuação social/profissional da instituição e, por isso, tem a capacidade de provar atividades institucionais, 
característica que, com efeito, aproxima a fotografia do conceito de documento arquivístico.

Dessa forma, para que se possa compreender o processo de inserção da fotografia na esfera dos arquivos - enquanto documento arquivístico derivado de uma atividade/ação institucional e com caráter probatório - propõe-se uma perspectiva de organização do conhecimento presente no documento fotográfico, tomando em consideração os processos administrativos institucionais que configuram sua produção e a decorrente evidenciação.

Para tanto, busca-se tratar a presença da fotografia no ambiente institucional como um documento que viabiliza, provar o cumprimento de suas funções e atividades e que, como tal, compõe o orbe de elementos documentais da chamada organização do conhecimento arquivístico (GUIMARÃES; TOGNOLI, 2015) ou organização do conhecimento em arquivos (TROITIÑO, 2018; HJØRLAND, 2016).

Para compor a perspectiva ora proposta optamos por adotar uma visão não meramente técnica e tópica do tratamento dado à fotografia, mas preferimos nos valer da noção de um processo institucional evidenciado como expressão da decorrência social desse documento que, como qualquer outro tipo de documento arquivístico, requer o estabelecimento de uma organização (tratamento) que interponha ou caracterize o "diálogo" (GUIMARÃES; TOGNOLI, 2015, p. 562) entre a sua produção, materialização e seu uso.

Em nossa proposta, iniciamos apresentando o contexto da fotografia na organização do conhecimento arquivístico, conforme a ótica em que estamos perspectivando - a fotografia produzida para fins institucionais. Nessa ótica, buscamos articular também a noção de domínio como elemento a ser analisado para se organizar o conhecimento transportado pela fotografia. Após isso, apresentamos nossas reflexões acerca de modos de organização a partir do já mencionado processo institucional de produção.

O artigo, em última análise, busca trazer à discussão uma perspectiva acerca da organização do conhecimento revestido nesses documentos fotográficos, cuja presença, nas instituições públicas e privadas brasileiras, se faz presente desde há muito tempo. O texto, ademais, não tem a pretensão de 
encerrar as discussões que se intensificaram a partir da década de 1970, no campo da Arquivologia, sobre como organizar as fotografias, mas pretende contribuir para novas reflexões a respeito do tema.

\section{O CONTEXTO DA FOTOGRAFIA NA ORGANIZAÇÃO DO CONHECIMENTO ARQUIVÍSTICO}

Para Hjørland (2003, 2016), a Organização do Conhecimento (OC) é concebida de forma dual a partir de dois sentidos epistêmicos, um relacionado às atividades de tratamento técnico documental, denominado sentido restrito; $\mathrm{e}$ outro, denominado sentido amplo, é concernente à organização do conhecimento alçada ao patamar de estruturações sociais.

Dessa forma, Hjørland (2008, p. 86, tradução nossa) argumenta que a OC no sentido amplo é caracterizada por tratar da "divisão social do trabalho, a organização das universidades e outras instituições de pesquisa e ensino superior, a estrutura das disciplinas e as profissões, a organização social dos meios de comunicação, a produção e disseminação do conhecimento. " Já no sentido restrito, a OC se faz presente em atividades, por assim dizer, técnicopráticas, como a descrição de documentos, indexação e classificação, ações e procedimentos realizados em bibliotecas, arquivos e outras instituições de cunho informacional, ou seja, sua preocupação está relacionada à construção e reconstrução de instrumentos e sistemas de organização de documentos. (HJØRLAND, 2008).

Partindo do sentido restrito proposto por Hjørland, entendemos que, na mesma acepção de Gnoli (2012) e Hjørland (2008), a OC, em sua função de organizar, está referida à organização de documentos de arquivo, bibliotecas, museus e outras instituições congêneres. Especificamente, a respeito de arquivos, Hjørland (2016) reconhece a independência epistemológica e institucional da Arquivologia - Archival Science como um campo científico e, ao mesmo tempo, reconhece esse campo como parte da OC, valendo-se da expressão Knowledge Organization in Archives. 
Hjørland (2016) também destaca que o domínio da Knowledge Organization in Archives, conta com um princípio de organização específico chamado princípio da proveniência. Utilizando uma citação coletada na Wikipédia, Hjørland (2016) descreve o princípio da proveniência como aquele que propõe que os documentos produzidos por uma mesma fonte devem ser mantidos juntos e sem confusão com documentos produzidos por outras fontes.

Já Guimarães e Tognoli (2015) abordam o referido princípio da proveniência desde de suas várias perspectivas, dentre as quais a histórica e a terminológica e, dessa forma, ressaltam a importância desse princípio como domínio que implica na forma específica (não temática) de se organizar o conhecimento arquivístico. Por outro lado, acreditamos que desde a perspectiva pós-Kuhniana de Hjørland, a visão do domínio estabelecida na proveniência poderia ser equiparada, talvez, com a prática cientifica no laboratório, tal como estudada por Latour e Woolgar (1979), considerando a produção de fatos no laboratório semelhante à produção arquivística em uma instituição.

Tomando como contexto de concepção da fotografia na organização do conhecimento arquivístico e a compreensão de OC como realizada em instituições como arquivos, bibliotecas e museus; mais a compreensão de que o princípio de proveniência constitui um domínio para a organização contextual do conhecimento arquivístico - compreendido institucionalmente pelo cumprimento das funções e atividades de seu produtor e evidenciado em documentos arquivísticos, queremos estabelecer uma abordagem metodológica para viabilizar nossa reflexão acerca da fotografia.

Dessa maneira, procuramos adotar a abordagem metodológica de Análise de Domínio (AD), que pode ser considerada como um processo para identificar os objetos existentes em um determinado domínio ou área do conhecimento para, com isso, obter a compreensão de seu contexto, de tal forma que seja possível representar e organizar o conhecimento ali produzido, e torná-lo pronto para ser utilizado. (HJØRLAND, 2002, 2004). Hjørland e Albrechtsen (1995) definem a $A D$ como:

[...] uma abordagem teórica de Ciência da Informação (Cl), que afirma, que a melhor forma de compreender as informações na 
ciência da informação é estudar as áreas de conhecimento como "comunidades de discurso", que são partes da divisão da sociedade do trabalho. Organização do conhecimento, estrutura, padrões de cooperação, linguagem e formas de comunicação, sistemas de informação e critérios de relevância são reflexões dos objetos do trabalho dessas comunidades e do seu papel na sociedade. A psicologia, o conhecimento, a necessidade de informação e critérios subjetivos de relevância devem ser vistos nesta perspectiva. (HJØRLAND; ALBRECHTSEN, 1995, p. 23, tradução nossa).

O complexo metodológico denominado análise de domínio é, neste contexto, compreendido como uma maneira de realizar pesquisa das comunidades científicas e de seus discursos. Chega-se, com a abordagem da $A D$, a "uma área de especialidade, ou um conjunto literário ou um grupo de pessoas trabalhando juntas numa organização" (MAI, 2005, p. 605), que para Smiraglia (2011) equivale à determinação do domínio, o que, por sua vez, corresponde à maneira pela qual novos conhecimentos são descobertos. Esses domínios em específico, aplicados à organização do conhecimento, são fundamentais para aprimorar as práticas informacionais, e prover melhorias nos serviços de informação, além de integrar diversos campos de pesquisa, apresentando abordagens sociais, funcionalistas e realistas.

Como meios de se aplicar a AD, Hjørland $(2002,2017)$ apresenta uma série de abordagens que, segundo o autor, não são exaustivas e nem excludentes, mas sim complementares, de acordo com critérios estabelecidos pelo domínio a ser analisado, são elas (segundo a versão, atualizada em 2017): 1. Produção de guias de literatura; 2 . Construção de classificações e tesauros especializados; Indexação e recuperação da informação especializada; 3. Estudos empíricos de usuários; 4. Estudos bibliométricos; 5. Estudos históricos; 6. Estudos de documentos e gêneros; 7. Estudos epistemológicos e críticos; 8. Estudos terminológicos, Linguagens para propósitos determinados, semântica de bases de dados e estudo dos discursos; 9. Estrutura e instituições da comunicação científica; 10. Cognição científica, conhecimento especialista e inteligência artificial; 11. Semântica em banco de dados; 12. Análise de discurso e, por fim, 13. Princípio da proveniência. 
Iremos nos apropriar, especificamente, das abordagens dos estudos de documentos e gêneros e do princípio da proveniência. Ao estudar os documentos e gêneros documentais que são criados em determinado domínio, acaba-se por representar a multidiversidade da produção de documentos, pois são gerados de acordo com as ações comunicativas, ou de acordo com as finalidades que objetivaram sua produção. O gênero, como já mencionado, refere-se a fotografia como registro. E esse estudo de documentos e gênero é aqui aplicado no interior do domínio do princípio da proveniência.

\section{O PRINCÍPIO DA PROVENIÊNCIA COMO BASE DO PROCESSO INSTITUCIONAL DE EVIDENCIAÇÃO DA ORGANIZAÇÃO DO CONHECIMENTO ARQUIVÍSTICO}

Para Guimarães e Tognoli (2015) a denominação archival knowledge organization é compreendida como todo o processamento teórico e técnico aplicados aos documentos arquivísticos, desde a sua criação até sua destinação final, incluindo o autor (pessoa que tem a competência para executar a ação), o usuário/destinatário que irá fazer uso do documento nas ações administrativas e o responsável pela organização dos documentos arquivísticos e o cumprimento dos trâmites administrativos.

Esta é uma abordagem que procura refletir a contextualização administrativa, histórica e social desses documentos, produzidos por qualquer instituição, e que se manifesta por meio de seriação orgânica. Diante dessa intepretação, foi possível levantar novos questionamentos para o campo da Arquivologia, e isso inclui pensar no seu próprio conhecimento produzido, enquanto sistemas de informação e compreendendo seu constructo social, aproximando-a assim como parte integrante da organização do conhecimento, pois, "existe a Arquivologia e seus diversos territórios, interpretações, intérpretes, métodos e práticas, ou talvez Arquivologias, no plural, dada a enorme influência histórica do Estado na construção do pensamento arquivístico" (JARDIM, 2017, p. 229). 
Ao se considerar a organização do conhecimento arquivístico, é possível perceber que o princípio da proveniência é o domínio específico para a ligação entre os campos independentes, pois conforme postula Hjørland (2016)

A organização do conhecimento em arquivos, no entanto, também deve ser considerada parte do KO, [...].Os arquivos podem conter registros oficiais, registros comerciais, imagens, cartas, diploma etc. O princípio específico de organização mais importante para esse domínio é o princípio da proveniência (HJØRLAND, 2016, p. 480, tradução nossa).

O princípio da proveniência é a base norteadora para as reflexões e práticas da Arquivologia, difundido e aceito pelas diferentes correntes de pensamento arquivístico, desde o século XIX e que, segundo argumento de Bellotto (2014, p 333), consiste na "conexão entre/nascimento dos documentos e o decantado respect des fonds dos franceses, ou seja, o princípio da proveniência, é inerente ao arquivo".

Para Duchein (1986, p. 14) por sua vez, o respect des fonds, "[...] consiste em manter agrupados, sem misturá-los a outros, os arquivos (documento de qualquer natureza) proveniente de uma administração [...]."Schellenberg (2006), Rousseau e Couture (1998), e Cruz Mundet (2001), aprofundam o conceito do princípio de proveniência ao trabalharem com a compreensão de uma proveniência externa e uma interna, ou seja, uma proveniência externa, ligada diretamente ao fundo de arquivo e a proveniência interna, atrelada à classificação e a ordenação dos documentos arquivísticos integrantes de um fundo.

Quanto ao primeiro aspecto, a proveniência externa, refere-se à instituição de maneira ampla, vinculada a missão da instituição refletida no corpus institucional. O segundo aspecto, a proveniência interna, está voltado para a organização dos documentos arquivísticos, ou seja, o interior do fundo, refletindo a estrutura das unidades administrativas e técnicas que são responsáveis pela produção dos documentos arquivísticos.

Nesse sentido, o fundo documental pode ser definido como um "conjunto de documentos de qualquer natureza reunidos rotineiramente e organicamente, criados e/ou acumulados e utilizados por uma pessoa física ou por uma família 
no exercício das suas atividades ou das suas funções" (ROUSSEAU; COUTURE, 1998, p. 91). Segundo Cook (1992), temos que observar o fundo documental como uma construção intelectual, não mais como uma estrutura física, pois,

\begin{abstract}
Os fundos, portanto, devem ser vistos primariamente como "uma construção intelectual". O fundo não é tanto uma entidade física nos arquivos, mas sim o resumo conceitual das descrições de entidades físicas no nível de série ou inferior, e as descrições do administrativo, caráter histórico e funcional do (s) criador (es) dos registros - bem como descrições dos processos de criação de registros (metadados). O fundo é, portanto, o todo conceitual que reflete um processo orgânico no qual um documento é produzido ou acumula a uma série de documentos que exibem uma unidade natural baseada em função, atividade, forma ou uso compartilhados. É o cerne desse processo ou relacionamento que liga o criador aos documentos que a essência da proveniência que pode ser encontrada e deve ser protegida. (COOK, 1992, p. 33, tradução nossa).
\end{abstract}

Dessa maneira, o objetivo do princípio da proveniência passa a ser entendido não apenas como método pragmático de organizar documentos, mas em seu escopo são inseridas as várias relações existentes entre os documentos, criadores e funções (DOUGLAS, 2016).

Nessas articulações em torno do fundo e do princípio da proveniência, podemos, ademais, reconhecer o lastro intitulado vínculo arquivístico, o archival bond conforme afirmaram Duranti (1997) e Tognoli e Guimaraes (2018).

Diante disto, cabe observar que desde que o princípio da proveniência foi concebido, ele segue sendo o principal qualificador da diferença entre os arquivos, enquanto configuração da organização do conhecimento arquivístico, e os demais sistemas de organização do conhecimento.

\title{
4 A ORGANIZAÇÃO DA FOTOGRAFIA INSTITUCIONAL
}

Antes de adentramos na discussão sobre a fotografia nos arquivos, fazse necessária a abordagem de compreensão em torno do documento arquivístico e algumas de suas especificidades. 
Para Delmas (2010, p. 129), o documento arquivístico "é aquele que, quaisquer que sejam sua data, sua forma e seu suporte que foi naturalmente criado ou recebido por uma pessoa física ou jurídica, pública ou privada, num dado momento, no decorrer e para o exercício de suas atividades habituais".

Sobre a definição, o autor procurou explicar que a origem de um documento arquivístico não é determinada pela sua forma, suporte ou tipo de escrita, código, mas sim, por ser um registro de uma ação institucional determinada. Sob essa premissa, o autor procura reafirmar que o documento arquivístico deve ser complementado pelo caráter de "informação orgânica". Dessa maneira, segundo ele, "as informações orgânicas, têm uma natureza própria, que não depende do suporte nem da escrita ou da antiguidade" (DELMAS, 2010, p.132).

Assim, no instante em que a informação foi produzida ou recebida por um organismo em suas rotinas/atividades administrativas, constitui-se em uma informação de arquivo/ informação arquivística - que é integrante do fundo de arquivo. (DELMAS, 2010). Por sua vez, Bellotto (2014), apresenta uma outra abordagem, acerca da informação arquivística, segundo a autora "o ponto básico da informação arquivística (à informação contida nos documentos arquivísticos), referentemente às informações de outra natureza: a de que ela é produzida dentro do contexto do exercício das funções/objetivos a que se propõem as entidades" (BELLOTTO, 2014, p. 298).

$\mathrm{Na}$ compreensão da autora, a informação arquivística possui relação direta com as competências e atividades das organizações, portanto, se configura com a gestão administrativa e com os compromissos que são requeridos pelo sistema jurídico. Essas considerações expõem a transcendência que envolve a produção do documento arquivístico, assim, há um lastro de informações jurídicas e administrativas que o prepara no tempo presente e que também o projeta para o futuro. (BELLOTTO, 2014).

Notamos que as abordagens não se excluem mas se complementam. Silva (2012), nessa linha, argumenta que a abordagem informacional teve seu início nos arquivos e na Arquivologia a partir da década 1980, sob a influência dinâmica das práticas e pela importância da informação na contemporaneidade, 
todavia, essa abordagem informacional para a Arquivologia não exclui a necessidade da existência de uma materialidade para à informação, ou seja, uma condição de evidência, que é "consignada ao registro com credibilidade e validade, para representar uma intencionalidade ou uma manifestação de vontade" (SILVA, 2012, p. 61).

Por isso, as pesquisas relacionadas à noção da informação arquivística se debruçam sobre a entidade documental, que é constituída de dois predicados materialidade - suporte - e informação- conteúdo- que, juntos, caracterizam o documento arquivístico. Dessa maneira, conforme postula Cruz Mundet (2001), as especificidades dos documentos de arquivos são: o caráter seriado, nos quais os documentos são produzidos um a um e com o passar do tempo, constituem séries documentais que são documentos produzidos derivados da mesma atividade; a gênese documental, que surge como um produto reflexo das atividades de seu produtor; a exclusividade, que consiste no fato de que a informação contida num documento raramente pode ser encontrada em outro com a mesma extensão e intensidade e, por fim, o inter-relacionamento de um documento de arquivo com outro é dada pelo seu pertencimento a um conjunto e pelas relações estabelecidas entre si.

Nesse sentido, Cortés Alonso (1980, p.18, tradução nossa) afirma que esses documentos são divididos em classes, sendo estas os "documentos textuais, sonoros ou de imagem, porque em qualquer uma dessas formas a documentação pode ser produzida". A autora apresenta as características do suporte, onde são registradas as informações, e o formato, a maneira de execução do registro, que, aliás, é o ponto crucial que fez com que a fotografia fosse apartada dos conjuntos documentais das instituições, pois pela fragilidade e especificidade de seu suporte foi incitada a preocupação com a conservação desses documentos ditos não tradicionais, ou de códigos díspares da linguagem escrita.

Destarte, no Brasil, as teóricas Paes e Marques (1977) e Paes (1986) definiram, no âmbito dos estudos nacionais, num primeiro momento, que as fotografias e arquivos fotográficos deveriam ser considerados "arquivos especiais", pois, os arquivos especiais são compreendidos como aqueles que 
têm sob sua guarda documentos em diferentes tipos de suportes e que, por esta razão, merecem tratamento especial, não apenas no que se refere ao seu armazenamento, como também, ao registro, classificação ou processamento, acondicionamento, controle e conservação. Entretanto, hoje, acreditamos que a compreensão de "arquivos especiais" deve ser revisada. Há inclusive, pesquisadores da área de Organização do Conhecimento, Ciência da Informação e Arquivologia, entre eles (SCHWARTZ, 1995; PARINET,1996; BARTLETT, 1996; LOPEZ, 2000; BUSHEY, 2005; LACERDA, 2008; MADIO, 2012, outros), discutindo a fotografia como documento arquivístico que, como tal, precisaria estar inserido nas funções arquivísticas, entre elas a classificação, processo de avaliação documental para descarte ou a guarda permanente e descrição.

A inserção das fotografias nos arquivos se verifica, de acordo com Boadas e Raset (2008), de quatro maneiras: na primeira as fotografias são produzidas pela própria instituição, que por diversas vezes acompanham um processo administrativo; na segunda elas são produzidas pelos fotógrafos que são contratados para uma reportagem pela própria instituição e estão relacionadas às atividades culturais ou promocionais; a terceira se dá pela aquisição ou compra do material fotográfico que tenha relação com o uso institucional; e a quarta se verifica por doações de acervos fotográficos, considerados de valor histórico para a instituição. Mesmo com todas essas formas de aquisição, Lopez (2011) argumenta que a organização arquivística para os documentos com imagens apresentam diferentes dificuldades, principalmente em relação aos princípios norteadores da área, tais como: princípio da proveniência (ordem atribuída pelo produtor do documento), que, como afirmamos, consiste no princípio que caracteriza a organização do conhecimento arquivístico e constitui um domínio para a instrumentalização de sua organização.

As fotografias nos arquivos, ao receberem ainda uma organização individualizada, reduzem a compreensão do significado global pelos quais esses documentos foram produzidos. Portanto, o contexto de produção dos documentos é essencial para propiciar aos pesquisadores a compreensão dos motivos que levaram à sua criação, sendo que é impossível serem percebidos 
somente através do conteúdo da imagem fotográfica, e também, com o referido contexto pode-se evitar a atribuição inadequada de prazos de guarda e destinação final, resultantes da identificação equivocada dos documentos. (LOPEZ; CARVALHO, 2013).

A respeito das dificuldades apresentadas para a manutenção do princípio da proveniência, são apresentadas possíveis práticas que eventualmente podem solucionar essas lacunas metodológicas. Schwartz (1995), a esse respeito, afirma que a diplomática contemporânea oferece subsídios para arquivistas efetuarem um trabalho reflexivo e um quadro metodológico com objetivo de contextualizar as fotografias com os demais documentos do arquivo, visto que, tradicionalmente esses documentos são descontextualizados.

No argumento da autora, as fotografias seriam inseridas no conceito de documento de arquivo na medida em que possuem uma escritura (realizada pela ótica ao registrar a imagem e ampliada pela química), sobre um suporte, que a vincula a uma evidência do teor documental e não pela veracidade do conteúdo visual) que de forma alguma se materializa em uma imagem isolada, mas em séries fotográficas, reafirmando, dessa maneira, o caráter serial dos arquivos. Assim, o caráter de autoridade, autenticidade e fidedignidade, para a autora, estão relacionados ao contexto funcional, ou seja, ao momento de criação e seu processo de evidenciação, importante para a compreensão e constituição de séries documentais que resultam da organização. Desde modo, a diplomática contemporânea pode ser um método útil para a compreensão das fotografias em um contexto funcional administrativo (SCHWARTZ, 1995).

Cabe ressaltar que a autora apresenta esta proposta conceitual para fotografias produzidas no modelo de produção físico-química. Contudo, as práticas fotográficas continuaram a evoluir, e com o advento da tecnologia, a partir da década de 1990, a produção de fotografias digitais trouxe uma nova realidade para os profissionais que produzem e organizam as imagens enquanto documento de arquivo.

Nesse sentido, se antes eram produzidos e acumulados negativos e ampliações - processos físico-químicos -, agora as fotografias são produtos de softwares e hardwares. Por esse motivo, é importante identificar aspectos e 
questionamentos relacionados a desmaterialização, compreendida como ausência de uma estrutura física da imagem, seja quanto aos aspectos morfológicos, relacionados a química, composição; assim como os fatores de conservação e preservação à longo prazo, entre outros (IGLÉSIAS I FRANCH, 2008).

Dessa maneira, os documentos arquivísticos nato digitais, sob a olhar da diplomática, são tidos como similares aos produzidos em papel, possuem "forma fixa, conteúdo estável, relação orgânica, contexto identificável, ação e o desenvolvimento de cinco pessoas, autor, redator, destinatário, originador e produtor" (RONDINELLI, 2013, p 235). Porém, garantir a manutenção da autenticidade dos documentos natos digitais têm sido um grande desafio, tendo em vista a facilidade de produção e transmissão desses documentos. O projeto Interpares ${ }^{[1]}$ tem realizado estudos acerca dos documentos de arquivos digitais, procurando desenvolver procedimentos e métodos para a solução do problema, apresentando PROPOSTAS como o controle de criação dos documentos em ambiente digital e a custódia dos documentos de arquivos nato digitais, incluindo a fotografia.

No Brasil, o Conselho Nacional de Arquivos - CONARQ, estabeleceu, pela a Resolução $n^{\circ}$ 20/2004, a elaboração e implementação de sistema de gestão eletrônica de documentos arquivísticos que engloba requisitos funcionais, metadados que estabelecem as garantias de integridade e acessibilidade de longo prazo aos documentos arquivísticos, além de outras medidas relacionadas ao documento arquivístico digital.

Considerando os documentos nato digitais, dentre os quais incluímos a fotografia digital, se pensarmos na aplicação das práticas que abrangem a produção dos documentos digitais, classificação, avaliação e transferência para a guarda permanente e a preservação a longo prazo, observamos a complexidade de fatores envolvidos.

Dessa maneira, a inserção da fotografia digital nos sistemas informatizados de Gestão Arquivística de Documentos (SIGAD) - (CONARQ Resolução e no 32; Resolução n³7) e nos Repositórios Arquivísticos Digitais Confiáveis (RDC-Arq) deve ocorrer sistematicamente, no entanto é necessário 
compreender a fotografia digital como documento arquivístico e contextualizá-la com os demais documentos produzidos e evidenciados institucionalmente.

A trajetória histórica das fotografias nos ambientes arquivisticos motivou uma classificação apartada dos demais documentos, devido a sua constituição documental. Nesse sentido, Iglésias e Franch (2004) menciona os aspectos que os profissionais e as instituições devem levar em consideração ao abordar a fotografia digital no ambiente arquivístico, assim:

[...] a necessidade do conhecimento e compreensão dos aspectos formais e tecnológicos, além dos atributos de ordem social das fotografias digitais; [...]. A metodologia arquivística e os princípios que devem apresentar uma visão geral que vai além da natureza física e lógica dos documentos produzidos e por fim, [...]. O problema da preservação a longo prazo, a principal premissa é a obrigação de trabalhar com padrões e formatos não proprietários. (IGLÉSIAS I FRANCH, 2004, sp., tradução nossa).

Tendo sido apresentadas essas notas a respeito da fotografia, convencional e digital, na organização do conhecimento arquivístico, passamos a destacar nossa reflexão acerca de um modo possível de se conceber a organização do conhecimento registrado (evidenciado) nas fotografias.

\subsection{O PROCESSO dE EVIDENCIAÇÃo NAS FotOGRAFIAS INSTITUCIONAIS}

Propomos que as fotografias, em primeiro lugar, e em consonância com os autores mencionados, devem ser consideradas documentos arquivísticos de pleno direito, sem a necessidade de apelarmos para as noções de arquivos especiais.

Decorrente disso, entendemos que a fotografia requer uma organização (classificação e descrição) que espelhe o seu processo de criação/produção documental a partir da estrutura e funcionamento da instituição, cuja atividade deve ser evidenciada, ou seja, viabilizada e provada pelo tipo fotográfico que decorrer de uma ou mais atividades institucionais. Porém, não há espaço aqui para tratarmos do tipo fotográfico, pois isso foge ao escopo do trabalho. Todavia, ressaltamos que tal tipo fotográfico se daria como uma evidenciação de uma 
atividade administrativa em si, e não somente como complemento de outro tipo documental concretizado em gênero textual, por exemplo.

Ao afirmarmos que a fotografia requer uma organização que reflita seu processo de produção, estamos evocando o princípio de proveniência como domínio, isto é, como um elemento configurador de uma comunidade discursiva, que aqui é considerada como equivalente a cada contexto institucional em específico, com seu quadro específico de funções e atividades.

Nessa perspectiva, cada instituição deveria, segundo nossa proposta, ser analisada e compreendida como um domínio especifico, ressaltando, e aqui está, talvez, o diferencial de nossa reflexão, que para nós o fator discursivo do domínio arquivístico poderia ser acrescido da práxis, ou seja, que deriva de um processo de trabalho dividido em funções e atividades administrativas, consubstanciado no processo de produção dos documentos arquivísticos. Entendemos que pelo fato da informação registrada no documento arquivístico referir-se à ação desempenhada pela instituição, seria mais adequado ressaltar o fator de uma ação prática da rotina de trabalho da instituição, e não só o aspecto comunicativo, uma vez, que a criação/produção do documento está relacionado a burocracia institucional.

Dessa forma, entendemos o domínio arquivístico como comunidade institucional de práxis que teria sua produção documental evidenciada nos documentos arquivisticos, incluindo, por conseguinte, a fotografia.

Chegando a este ponto, ressaltamos que a fotografia deve ser indistintamente tratada como resultado do processo de produção documental institucional e sempre vinculada a uma atividade institucional, e sua organização deve se pautar igualmente nesse processo, ou seja, dentro do domínio do princípio da proveniência.

A imagem que a fotografia veicula, nesse sentido, deve ser considerada um índice do referido processo e não o elemento único de organização. Assim, para que o diálogo entre o contexto de produção e o uso, tal como mencionado anteriormente, seja efetivo e condizente com o que é próprio do documento arquivístico, propomos que a organização do conhecimento arquivístico e, em especial, do conhecimento arquivístico evidenciado pelos conjuntos que tenham 
fotografias, sejam regidos pela análise de cada domínio configurado a partir do princípio da proveniência, de acordo com o processo institucional de evidenciação do conhecimento.

\section{CONSIDERAÇÕES FINAIS}

No estudo de $O C$ desde a perspectiva da $A D$, interpretada em termos de aplicação do princípio da proveniência, buscamos levar em conta a ótica formada a partir da abordagem de estudo de documentos e gêneros de Hjørland (2002, 2017) e princípio da proveniência de Tognoli e Guimarães (2018). O princípio da proveniência é norteador para análise do domínio na organização do conhecimento arquivístico. Decorrente disso, em nossa proposta compreendemos que cada instituição deveria ser analisada como um domínio específico, pois assim o fator discursivo já sedimentado no domínio arquivístico deverá ser acrescido pela práxis, pois, a práxis no domínio arquivístico que é aqui definido como processo de trabalho, dividido no cumprimento de funções e atividades jurídicas e administrativas no qual se evidencia na geração de documentos.

Entendemos que, pelo fato da informação registrada no documento arquivístico referir-se à ação desempenhada pela instituição, seria mais adequado ressaltar $\mathrm{o}$ fator de ação prática, e não somente o aspecto comunicativo, pois, a partir do princípio da proveniência iniciam-se reflexões e práticas empíricas arquivísticas, tendo como premissa a identificação do contexto de produção dos documentos produzidos, interpretando a acumulação orgânica dos mesmos, e estabelecendo a sua organização externa e interna como base para as funções arquivísticas, dentre elas a classificação e descrição/representação.

Tal entendimento foi oficializado pelo CONARQ, por intermédio da Câmara Técnica de Documentos Audiovisuais, Iconográficos e Sonoros que lançou em 2014 a Resolução de número 41, que dispõe sobre a gestão de documentos dos documentos audiovisuais, iconográficos, sonoros e musicais 
em programas de gestão de documentos arquivísticos dos órgãos e entidades integrantes do Sistema Nacional de Arquivos - SINAR.

Dessa maneira, temos este princípio como primordial, pois diferencia e evidencia o domínio da organização do conhecimento arquivístico perante as demais formas de organização do conhecimento.

Já quanto às concepções que permeiam o problema de se considerar a fotografia como documento arquivístico, já é dado presente no quadro teórico da Arquivologia, sendo que a literatura do campo tem apresentado possíveis "soluções", como a aproximação metodológica da diplomática contemporânea, sobretudo, quando se parte de questões relacionadas à resistência em se considerar a fotografia como registro que evidencia o ato da execução de uma atividade institucional.

Destarte, esse dado, sobre a contextualização da fotografia no domínio da organização do conhecimento arquivístico pode contribuir com aportes para melhor se pensar a acepção da fotografia no âmbito da teoria arquivística, pois tomar a decisão simplista de categorizar como arquivos especiais não é mais condizente com a dinâmica da produção de documentos arquivisticos contemporaneamente.

Ressaltamos que a diplomática contemporânea, torna-se fundamental, em vista da complexidade da produção desse documento arquivístico, tanto em meio analógico como em meio digital.

Desse modo, os estudos de documentos e gênero sob o viés da Arquivologia é promissor, pois com aos avanços das tecnologias de informação há a necessidade da manutenção da autenticidade dos documentos arquivísticos natos digitais, e isso cria novas inquietações e incertezas para a Arquivologia e para os arquivistas.

\section{REFERÊNCIAS}

BARTLETT, N. Diplomatics for Photographic Images: Academic Exoticism? American Archivist. v, 59. p. 486- 494, 1996. 
BAUDELAIRE, C. Selected writings on arts and artists. Cambridge: Cambridge University Press. 1972.

BELLOTTO, H. L. Arquivos: estudos e reflexões. Belo Horizonte: Editora UFMG, 2014.

BOADAS I RASET. J. Patrimonio Fotográfico: Estrategias para su gestión. Revista de los museos de Andalucía, n. 9, p. 28-31, fev. 2008.

BUSHEY, J. E. Born Digital Images as Reliable and Authentic Records. 2005.Tese (Master of Archival Studies) the University Of British Columbia, Aug. 2005.

CONSELHO NACIONAL DE ARQUIVOS (BRASIL). Resolução $n^{\circ}$ 20, 16 de Julho de 2004. Dispõe sobre a inserção dos documentos digitais em programas de gestão arquivística de documentos dos órgãos e entidades integrantes do Sistema Nacional de Arquivos- SINAR. Rio de Janeiro, 2004. Disponível em: http://conarq.arquivonacional.gov.br/resolucoes-do-conarq/262resolucao-n-20,-de-16-de-julho-de-2004.html. Acesso em 06 dez. 2019.

CONSELHO NACIONAL DE ARQUIVOS (BRASIL). Resolução $n^{\circ} \mathbf{2 5}$, de 27 abril de 2007. Dispõe sobre a adoção do Modelo de Requisitos para Sistemas Informatizados de Gestão Arquivística de Documentos - e-ARQ Brasil pelos órgãos e entidades integrantes do Sistema Nacional de Arquivos - SINAR. Rio de Janeiro, 2007. Disponível em:

http://conarq.arquivonacional.gov.br/resolucoes-do-conarq/267-resolucao-n-25,de-27-de-abril-de-2007.html. Acesso em: 06 dez. 2019.

CONSELHO NACIONAL DE ARQUIVOS (BRASIL). Resolução $n^{\circ}$ 32, de 17 de maio de 2010. Dispõe sobre a inserção dos Metadados na Parte II do Modelo de Requisitos e-ARQ Brasil. Rio de Janeiro, 2010. Disponível em: http://conarq.arquivonacional.gov.br/resolucoes-do-conarq/274-resolucao-n-32,de-17-de-maio-de-2010.html. Acesso em: 06 dez. 2019.

CONSELHO NACIONAL DE ARQUIVOS (BRASIL). Resolução $n^{\circ}$ 37, de 19 de dezembro de 2012. Diretrizes para a Presunção de Autenticidade de Documentos Arquivísticos Digitais. Rio de Janeiro, 2012. Acesso em: http://conarq.gov.br/images/publicacoes_textos/conarq_presuncao_autenticidad e_completa.pdf. Acesso em: 06 dez.2019.

CONSELHO NACIONAL DE ARQUIVOS (BRASIL). Resolução n³9, de 29 de abril de 2014. Estabelece diretrizes para a implementação de repositórios arquivísticos digitais confiáveis para o arquivamento e manutenção de documentos arquivísticos digitais em suas fases corrente, intermediária e permanente, dos órgãos e entidades integrantes do Sistema Nacional de Arquivos - SINAR. Rio de Janeiro, 2014. Disponível em:

http://conarq.arquivonacional.gov.br/resolucoes-do-conarq/281-resolucao-n-39de-29-de-abril-de-2014.html. Acesso em: 06 dez. 2019 
CONSELHO NACIONAL DE ARQUIVOS (BRASIL). Resolução $n^{\circ} 41$ de 9 de dezembro de 2014. Dispõe sobre a inserção dos documentos audiovisuais, iconográficos, sonoros e musicais em programas de gestão de documentos arquivísticos dos órgãos e entidades integrantes do Sistema Nacional de Arquivos - SINAR, visando a sua preservação e acesso. Rio de Janeiro, 2014. Disponível em: http://conarq.arquivonacional.gov.br/resolucoes-do-conarq/283resolucao-n-41,-de-9-de-dezembro-de-2014.html. Acesso em: 06 dez. 2019

COOK, T. The Concept of the Archival Fonds in the Post-Custodial Era: Theory, Problems and Solutions. Archivaria, n. 35. p. 24-37, 1992.

CORTÉS ALONSO, V. Documentación y Documentos. Ministério de Cultura, Direção General de Bellas Artes Archivos y Bibliotecas, Subdirección General de Archivos, 1980.

CRUZ MUNDET, J. R. Manual de archivistica. 4. Ed. Madrid: Fundación Germán Sánchez Ruipérez, 2001.

DELMAS, B. Arquivos para quê? textos escolhidos. São Paulo: Instituto Fernando Henrique Cardoso, 2010.

DOUGLAS, J. Ideias em evolução sobre o princípio da proveniência. In: EASTWOOD, T. MACNEIL, H. (orgs.).Correntes atuais do pensamento arquivístico. Belo Horizonte: Editora UFMG, 2016, p. 47-74.

DUCHEIN, M. O respeito aos fundos em Arquivística: princípios teóricos e problemas práticos. Arquivo \& Administração, Rio de Janeiro, v. 10 -14, n. 1, abr. 1986.

DURANTI, L. The Archival Bond. Archives and Museum Informatics, n.11, p. 213-218, 1997.

GNOLI, C. Metadata About What? Distinguishing Between Ontic, Epistemic, and Documental Dimensions in Knowledge Organization. Knowledge

Organization, v. 39, n. 04, p. $268-275,2012$.

GUIMARÃES, J. A. C.; TOGNOLI, N. B. Provenance as a Domain Analysis Approach in Archival Knowledge Organization. Knowledge Organization, v. 42, n. 8, p. $562-569,2015$.

HJØRLAND, B; ALBRECHTSEN, H. Toward a New Horizon in Information Science: Domain-Analysis. Journal of the American Society for Information Science, v. 46, n. 6, p. 400-425, jul. 1995.

HJØRLAND, B. Domain analysis in information science: Eleven approaches Traditional as well as innovative. Journal of Documentation, v. 58, n. 4, p. 422-462, jan. 2002. 
HJØRLAND, B. Domain analysis: a socio-cognitive orientation for Information Science research. Bulletin of the American Society for Information Science and Technology, v. 30, n.3, Feb./Mar. 2004. Disponível em:

http://www.asis.org/Bulletin/Feb-04/hjorland.html. Acesso em: 13 de mar. 2017.

HJØRLAND, B. Fundamentals of knowledge organization. Knowledge

Organization, v. 30, n. 2, p. 87-111, 2003.

HJØRLAND, B. What is Knowledge Organization (KO)?. Knowledge

Organization, v. 35, n. 2/3, p. 86-101, 2008.

HJøRLAND, B. Knowledge Organization (KO). Knowledge Organization, $v$ .43 , n. 6 , p. $475-484,2016$.

HJøRLAND, B. Domain Analysis. Knowledge Organization, v. 44, n. 4, p. 436-469, 2017.

IGLÉSIAS, I; FRANCH, D. La gestión de la imagen digital. Hipertext.net, n. 2, 2004. Disponível em: https://www.upf.edu/hipertextnet/numero-

2/imagen_digital.html. Acesso em: 23 de fev. 2016.

IGLÉSIAS, I; FRANCH, D. La fotografía digital en los archivos: que es y como se trata. Gijón: Editora Trea, 2008.

JARDIM, J. M. A pesquisa em Arquivologia: métodos, especificidades e Diálogos. In: SANTOS, E. C. dos (org.) Pesquisa em Arquivologia fronteiras e perspectivas epistemológicas. Campina Grande: EDUEPB, 2017. p. 221238.

LACERDA, A. L. A fotografia nos arquivos: a produção dos documentos fotográficos na Fundação Rockefeller durante o combate à febre amarela no Brasil. 2008. Tese (Doutorado em História Social) - Faculdade de Filosofia, Letras e Ciências Humanas da Universidade de São Paulo, São Paulo, 2008.

LATOUR, B.; WOOLGAR, S. Laboratory life: The Construction of Scientific Facts. Princeton: Princeton University Press. 1979.

LOPEZ, A. P. A. Contextualización archivística de documentos fotográficos archival contextualization of photographic documents. Alexandria: Revista de Ciencias de la Información, año V, n.8, enero-diciembre 2011. Disponível em: http://revistas.pucp.edu.pe/index.php/alexandria/article/view/213/207_Acesso em: 13 de jul. de 2015.

LOPEZ, A. P. A. As Razões e os Sentidos: Finalidades da Produção Documental e Interpretação de conteúdos na Organização Arquivística de documentos Imagéticos. 2000. Tese (Doutorado em História Social) Faculdade de Filosofia e Ciências Humanas da Universidade de São Paulo, São Paulo, 2000. 
LOPEZ, A. P. A.; CARVALHO, P. D. S. A classificação arquivística por assunto em documentos fotográficos: o exemplo do Arquivo Público do Distrito Federal. Perspectivas em Gestão \& Conhecimento, v. 3, n. 2, p. 271-279, 2013.

MAI, J.-E. Analysis in indexing: document and domain centered approaches. Information Processing and Management, v. 41, p. 599-611, 2005.

MADIO, T. C de C. Uma Discussão dos Documentos Fotográficos em Ambiente de Arquivo. In: Valentim. M. L. P. (org.), Estudos Avançados em

Arquivologia. Marília: Oficina Universitária: São Paulo: Cultura Acadêmica, 2012, p. $55-68$.

PAES, M. L.; MARQUES, E. H. R. Arquivos Fotográficos. Arquivo \& Administração, Rio de Janeiro, v. 5, n. 2, p. 17-19, 1977.

PAES. M.L.; Arquivo: teoria e prática. Rio de Janeiro: Editora FGV, 1986.

PARINET, E. Diplomatics and Institutional Photos. American Archivist, vol. 59, p. 480-485, 1996.

RONDINELLI, R. C. $O$ documento arquivístico ante a realidade digital: uma revisão conceitual necessária. Rio de Janeiro: Editora FGV, 2013.

ROUSSEAU, J. Y.; COUTURE, C. Os Fundamentos da disciplina arquivística. Lisboa: Publicações Dom Quixote, 1998.

SCHELLENBERG, T. R. Arquivos Modernos: princípios e técnica. Rio de Janeiro: Editora FGV, 2006.

SCHWARTZ, J. M. We make our tolls and our tools make us. Lessons from photography for the practice, politics and poetics of diplomatics. Archivaria, $n$. 40, p. 40-74, 1995.

SILVA, E. P. da. A noção de informação arquivística. In. RODRIGUES, G.M.; COSTA, M. G. da. (orgs.), Arquivologia: configurações da pesquisa no Brasil: epistemologia, formação, preservação, uso e acesso. Brasília, 2012, p. 37-68.

SMIRAGLIA, R. P. Domain coherence within Knowledge Organization: people, interacting theoretically, across geopolitical and cultural boundaries. In:

ANNUAL CAISIACSI CONFERENCE, 39., June 2-4, 2011, Canada, Proceedings... Canada: University of New Brunswick, p. 1-6, 2011.

SONTAG, S. Sobre Fotografia. São Paulo: Companhia das Letras. 2004.

TAGG, J. El peso de la representación: ensayos sobre fotografias e historias. Barcelona: Gustavo Gilli. 2007. 
TOGNOLI. N. B.; GUIMARÃES, J.A.C. Provenance. In: Encyclopedia of Knowledge Organization. 2018. Disponível em:

http://www.isko.org/cyclo/provenance. Acesso: 12 de jan. de 2019.

TROITIÑO, S. Different parameters for Knowledge Organization in archives. In: Challenges and Opportunities for Knowledge Organization in the Digital Age, p.160-166, 2018.

\title{
INSTITUTIONAL PHOTOGRAPHY IN ARCHIVAL KNOWLEDGE ORGANIZATION: UNDERSTANDING THE PROCESS OF DOCUMENT EVIDENCE AS AN ORGANIZATIONAL PARAMETER
}

\begin{abstract}
Introduction: The consideration of photographs in the framework of archival documents is relatively recent. In this sense, photography stills find methodological theoretical difficulties regarding the applications of the basic functions of Archival Science. In this sense, it is necessary to reflect on this type of document in the archival knowledge organization. Objective: to reflect on photography in the archival knowledge organization, presenting the peculiarities of the processing that involves this type of document in conventional and digital media and a reflection on its organization based on the process of evidence in the institutional production. Methodology: A qualitative methodological approach of theoretical and reflexive nature. Results: An approach that considers the principle of provenance as an element of analysis to identify the work process that is evidenced in the photographic archival document as a communicative aspect and, above all, an aspect of praxis. Conclusions: Based on the identification of this process, we suggest a conception of knowledge organization recorded in the photographs that favors the dialogue between the context of production and the context of use of this document.
\end{abstract}

Descriptors: Archival Science. Knowledge organization. Photography. Archival document.

\section{LA FOTOGRAFÍA INSTITUCIONAL EN LA ORGANIZACIÓN DEL CONOCIMIENTO ARCHIVÍSTICO: COMPRENSIÓN DEL PROCESO DE EVIDENCIA DOCUMENTAL COMO PARÁMETRO DE ORGANIZACIÓN}

\section{RESUMEN}

Introducción: La inserción de la fotografía en el cuadro de los documentos de archivo es relativamente reciente. En este sentido, la fotografía todavía presenta problemas teóricos-metodológicos con respecto a la aplicación de las funciones básicas de la 
A fotografia institucional na organização do conhecimento arquivístico: compreendendo o processo de evidenciação documental como parâmetro de organização

archivística. En este sentido, es necesario reflexionar sobre este documento en la organización del conocimiento archivístico. Objetivo: Reflexionar sobre la fotografía en la organización del conocimiento archivístico, presentando las peculiaridades del tratamiento de este tipo de documento en soporte convencional y digital, así como sobre su organización a partir de su proceso de divulgación en la producción institucional. Metodología: Investigación de naturaleza cualitativa, teórica y reflexiva. Resultados: Se presenta un enfoque que considera el principio de procedencia como elemento de análisis para identificar el proceso de trabajo evidenciado en el documento de archivo fotográfico como un aspecto comunicativo $\mathrm{y}$, sobre todo, como un aspecto de la praxis. Conclusiones: a partir de la identificación de este proceso, se sugiere una concepción de la organización del conocimiento registrado en la fotografía que favorezca el diálogo entre el contexto de producción y el contexto de uso de este documento.

Descriptores: Archivística. Organización del conocimiento. Fotografia. Documento de archivo. 